Article

\title{
Targeting Death Receptor TRAIL-R2 by Chalcones for TRAIL-Induced Apoptosis in Cancer Cells
}

\author{
Ewelina Szliszka $^{\dagger}$, Dagmara Jaworska ${ }^{\dagger}$, Malgorzata Kłósek, Zenon P. Czuba and \\ Wojciech Król *
}

Chair and Department of Microbiology and Immunology, Medical University of Silesia in Katowice, Jordana 19, 41-808 Zabrze, Poland; E-Mails: eszliszka@sum.edu.pl (E.S.); djaworska@sum.edu.pl (D.J.); klosekmalgorzata@gmail.com (M.K.); zczuba@sum.edu.pl (Z.P.C.)

$\dagger$ These authors contributed equally to this work.

* Author to whom correspondence should be addressed; E-Mail: wkrol@ sum.edu.pl; Tel./Fax: +48-322-722-554.

Received: 24 October 2012; in revised form: 13 November 2012 / Accepted: 14 November 2012 / Published: 20 November 2012

\begin{abstract}
Tumor necrosis factor-related apoptosis-inducing ligand (TRAIL) induces apoptosis in cancer cells without toxicity to normal cells. TRAIL binds to death receptors, TRAIL-R1 (DR4) and TRAIL-R2 (DR5) expressed on cancer cell surface and activates apoptotic pathways. Endogenous TRAIL plays an important role in immune surveillance and defense against cancer cells. However, as more tumor cells are reported to be resistant to TRAIL mediated death, it is important to search for and develop new strategies to overcome this resistance. Chalcones can sensitize cancer cells to TRAIL-induced apoptosis. We examined the cytotoxic and apoptotic effects of TRAIL in combination with four chalcones: chalcone, isobavachalcone, licochalcone A and xanthohumol on HeLa cancer cells. The cytotoxicity was measured by MTT and LDH assays. The apoptosis was detected using annexin V-FITC staining by flow cytometry and fluorescence microscopy. Death receptor expression was analyzed using flow cytometry. The decreased expression of death receptors in cancer cells may be the cause of TRAIL-resistance. Chalcones enhance TRAIL-induced apoptosis in HeLa cells through increased expression of TRAIL-R2. Our study has indicated that chalcones augment the antitumor activity of TRAIL and confirm their cancer chemopreventive properties.
\end{abstract}


Keywords: TRAIL; chalcones; apoptosis; death receptors; cancer cells; chemoprevention

\section{Introduction}

The death ligand TRAIL (tumor necrosis factor-related apoptosis-inducing ligand), a member of the TNF superfamily is recognized as a promising anticancer agent due to selective killing of cancer cells without toxicity to normal cells [1]. TRAIL plays an important role in immune surveillance and defense mechanisms against tumor cells. The death ligand is expressed on the T lymphocytes, natural killer cells, dendritic cells, neutrophils, monocytes or macrophages [2,3]. Membrane-bound TRAIL can be cleaved from the cell surface into a soluble secreted form [1,4]. Endogenous TRAIL triggers apoptosis in cancer cells via receptor-mediated death through interaction with the death receptors (DRs) [5]. There are two agonistic transmembrane receptors, TRAIL-R1/DR4 and TRAIL-R2/DR5, which bind ligands by extracellular domains. The death receptors contain complete and functional cytoplasmic death domains responsible for the activation of apoptotic pathway in cancer cells $[5,6]$. The downstream signaling cascade includes receptor oligomerization, recruitment of the adaptor molecule FADD (Fas-associated death domain) with formation of the DISC (death inducing signaling complex), activation of initiator caspases, cleavage of effector caspases and finally DNA fragmentation [6-8].

However, some tumor cells are resistant to TRAIL-mediated death [8-10]. Failure to undergo apoptosis has been implicated in the resistance of cancer cells to TRAIL surveillance and therefore in tumor development [11]. The expression of the death receptors on cancer cell surface is involved in TRAIL-resistance [5,6,9]. TRAIL-R2 called "KILLER" receptor is a crucial player in the transduction of apoptotic signaling in cancer cells derived from solid tumors $[4,12]$. We and others have shown that TRAIL-resistant cancer cells can be sensitized by polyphenols [13-16].

Chalcones (1,3-diphenyl-2-propen-1-ones) represent an important group of the polyphenolic family widespread in various spices, fruits, vegetables, tea or beer [17-19]. Isobavachalcone is found in various medicinal plants, such as Psoralea corylifolia, Angelica keiskei and Broussonetia papyrifera. Licochalcone A is isolated from root of herb named licorice (Glycyrrhiza glabra, Glycyrrhiza uralensis). Xanthohumol is identified in hops (Humulus lupulus), an essential raw material for beer brewing [20-25]. Chemically, they are open-chain flavonoids bearing two aromatic rings joined by a three-carbon $\alpha, \beta$-unsaturated carbonyl system [25-29].

Chemoprevention is a method of tumor control in which malignancy is prevented or reversed by nutritional or pharmacological intervention using natural or synthetic substances [16,30]. The role of polyphenols in cancer prevention has been confirmed in numerous laboratory, clinical and epidemiological studies [16,31]. The in vitro and in vivo experiments provide the evidence that chalcones target the multistep carcinogenetic process by scavenging reactive oxygen species, regulating cell proliferation, inducing apoptosis, inhibiting tumor invasion and metastasis, blocking angiogenesis and affecting metabolism of xenobiotics [17,18,32].

Our previous findings demonstrated that chalcones and dihydrochalcones augment TRAIL-mediated apoptosis in LNCaP prostate cancer cells [33,34]. The present study is a continuation of these 
investigations and exploration of the mechanism of action exhibited by chalcones on TRAIL-mediated apoptosis. Now we examine the cytotoxic and apoptotic effects of TRAIL in combination with four chalcones: chalcone, isobavachalcone, licochalcone A and xanthohumol on HeLa cervical cancer cells. The chemical structures of the tested compounds are shown in Figure 1. We report the molecular mechanism by which these chalcones enhance TRAIL-induced apoptosis in cancer cells. The obtained results suggest that the overcoming of TRAIL-resistance by chalcones may be one of the mechanisms responsible for their cancer chemopreventive activities.

Figure 1. Chemical structures of the studied chalcones.<smiles>O=C(/C=C/c1ccccc1)c1ccccc1</smiles>

Chalcone $(\mathbf{C H})$<smiles>C=CC(C)(C)c1cc(/C=C/C(=O)c2ccc(O)cc2)c(OC)cc1O</smiles>

Licochalcone A (LC)<smiles>CC(C)=CCc1c(O)ccc(C(=O)/C=C/c2ccc(O)cc2)c1O</smiles>

Isobavachalcone (IC)<smiles>COc1cc(O)c(CC=C(C)C)c(O)c1C(=O)/C=C/c1ccc(O)cc1</smiles>

Xanthohumol (XH)

\section{Results and Discussion}

\subsection{Cytotoxic and Apoptotic Activities of TRAIL in HeLa Cancer Cells}

TRAIL is an important component of the immune defense and powerful inducer of apoptosis in cancer cells [35]. Active avoidance of apoptosis promoting cancer cells survival is one of the hallmarks of tumor development $[1,4,36]$. Many type of cancer cell lines are TRAIL-resistant $[9,16,37]$.

We and others have demonstrated that the HeLa cell line is also resistant to TRAIL-mediated death $[13,15,38,39]$. Recombinant human TRAIL used in our study is a soluble protein based on a natural endogenous ligand [38,39]. TRAIL at the concentration of $100 \mathrm{ng} / \mathrm{mL}$ induced $9.42 \% \pm 0.9 \%$ cell death. The cytotoxicity was measured by MTT assay. This ligand causes the cytotoxic effect in cancer cells via the apoptotic route [13]. The necrotic cell death percentage of HeLa cells examined by lactate dehydrogenase assay, by flow cytometry with propidium iodide and by fluorescence microscopy with Ethidium Homodimer III was near $0 \%$. The apoptotic activity of TRAIL at the concentration of $100 \mathrm{ng} / \mathrm{mL}$ was $14.4 \% \pm 0.9 \%$. TRAIL concentrations of $200 \mathrm{ng} / \mathrm{mL}$ or higher did not significantly increase the cytotoxic and apoptotic effects on HeLa cells. 


\subsection{Cytotoxic and Apoptotic Activities of Chalcones in HeLa Cancer Cells}

Chalcones have been recently subject of great interest for their pharmacological activities, such as anti-inflammatory, antioxidant, anticancer and chemopreventive properties. Therefore, the application of natural or synthetic chalcones is becoming increasingly recognized as an effective strategy in cancer prevention and therapy [17,18,27-29].

We tested anticancer activity of chalcones at the concentrations of $25 \mu \mathrm{M}$ and $50 \mu \mathrm{M}$ against HeLa cells. The compounds induce cytotoxic and apoptotic effects in a dose-dependent manner. The cytotoxicity of chalcones in HeLa cells was: $6.3 \% \pm 1.2 \%-9.4 \% \pm 0.9 \%$ cell death for chalcone, $7.0 \% \pm 1.4 \%-13.9 \% \pm 1.4 \%$ cell death for isobavachalcone, $7.8 \% \pm 1.4 \%-17.4 \% \pm 1.7 \%$ cell death for licochalcone A, $14.5 \% \pm 1.4 \%-25.8 \% \pm 2.1 \%$ cell death for xanthohumol (Figure 2A).

Figure 2. Cytotoxic and apoptotic effects of chalcones in HeLa cancer cells. The cells were incubated for $24 \mathrm{~h}$ with chalcones at the concentrations of $25 \mu \mathrm{M}$ and $50 \mu \mathrm{M}$. The values represent mean $\pm \mathrm{SD}$ of three independent experiments performed in quadruplicate (*** $p<0.001$ compared with control). (a) Cytotoxic activity of chalcones in HeLa cells. The percentage of cell death was measured by MTT cytotoxicity assay; (b) Apoptotic activity of chalcones in HeLa cells. Detection of apoptotic cell death by annexin V-FITC staining using flow cytometry.
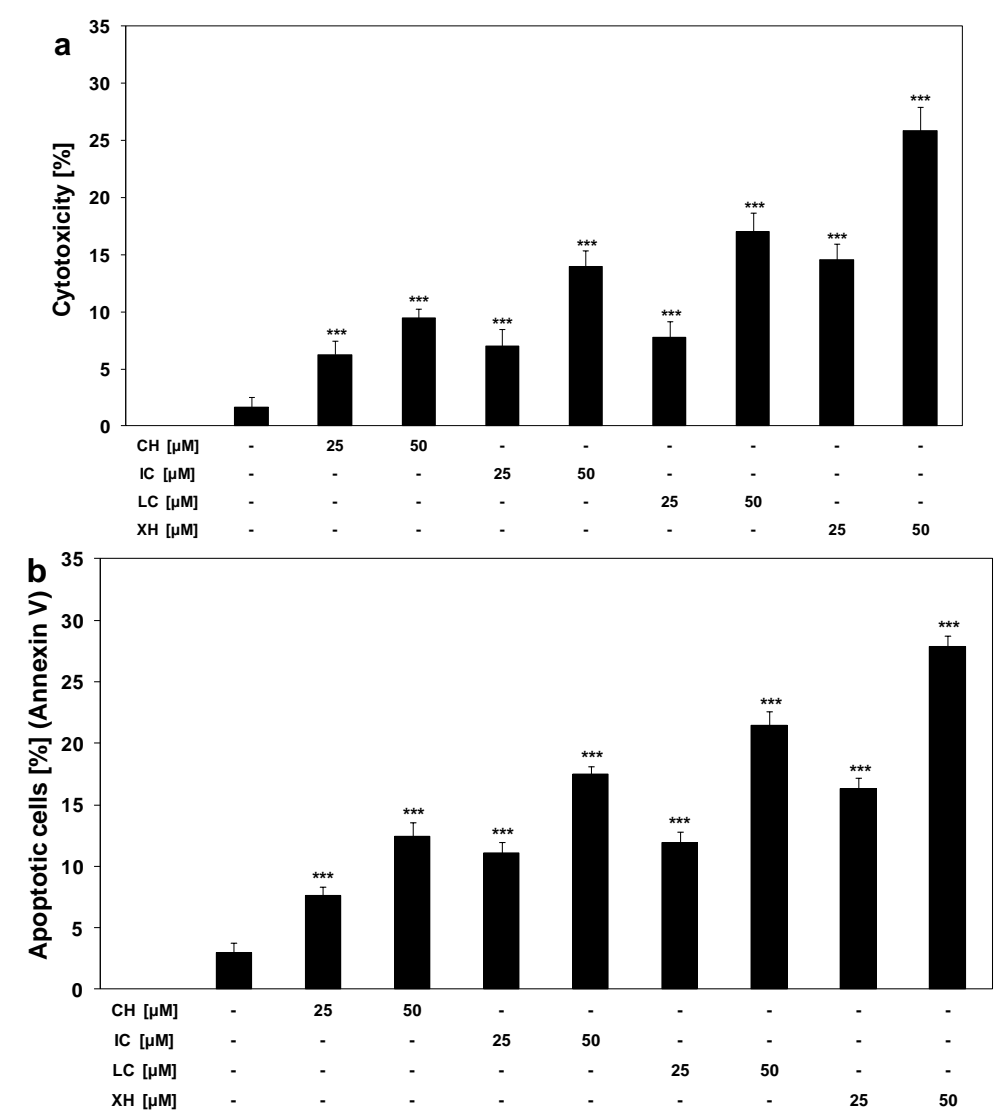

Our results indicate that this cytotoxic effect was mediated through apoptosis. The percentage of necrotic cells examined by lactate dehydrogenase assay and fluorescence microscopy with Ethidium Homodimer III was near $0 \%$. Chalones cause apoptosis in HeLa cells: $7.6 \% \pm 0.7 \%-12.5 \% \pm 1.1 \%$ 
cell death for chalcone, $11.1 \% \pm 0.9 \%-17.5 \% \pm 0.6 \%$ cell death for isobavachalcone, $11.9 \% \pm 0.9 \%-21.4 \% \pm 1.2 \%$ cell death for licochalcone A, $16.3 \% \pm 0.8 \%-27.8 \% \pm 0.9 \%$ cell death for xanthohumol (Figure 2B).

Chalcone arrests cell cycle and triggers apoptosis in T24, HT1376 bladder cancer cells and MCF7 and MDA-MD231 breast cancer cells [40,41]. Isobavachalcone shows an anti-proliferative and pro-apoptotic activities against OVAR8 ovarian and PC3 prostate cancer cells, and against IMR32, NB39 neuroblastoma cells [42,43]. Licochalcone A blocks cell cycle progression and induces apoptosis in PC3 prostate cancer cells [23]. Xanthohumol exhibits growth inhibitory and apoptosis-inducing effects on OVAR and SKOV3 ovarian cancer cell lines and on LNCaP, DU145 and PC3 prostate cancer cell lines $[44,45]$.

\subsection{Cytotoxic and Apoptotic Activities of TRAIL in Combination with Chalcones in HeLa Cancer Cells}

Induction of cancer cell-specific apoptosis via activation of TRAIL signaling has become an important focus of cancer research [1,4]. Deregulation of the TRAIL-mediated apoptotic pathway is significant in the initiation and progression of malignancy $[1,11,46]$. However, as more tumor cells are reported to be resistant to TRAIL-induced death, it is important to identify compounds that potently restore TRAIL-sensitivity. Chalcones have been shown to sensitize cancer cells to TRAIL-induced apoptosis [33,34,47-50].

We investigated the cytotoxic and apoptotic effects of TRAIL in combination with chalcones on HeLa cancer cells. The cytotoxicity of TRAIL at the concentration of $100 \mathrm{ng} / \mathrm{mL}$ in combination with chalcones at the concentrations of $25 \mu \mathrm{M}$ and $50 \mu \mathrm{M}$ in HeLa cells was significantly increased to $31.3 \% \pm 1.3 \%-41.6 \% \pm 1.2 \%$ cell death for chalcone, to $48.2 \% \pm 1.9 \%-63.8 \% \pm 1.1 \%$ cell death for isobavachalcone, to $58.6 \% \pm 1.6 \%-71.3 \% \pm 1.2 \%$ cell death for licochalcone $\mathrm{A}$, and to $62.7 \% \pm 1.6 \%-73.8 \% \pm 2.0 \%$ cell death for xanthohumol in comparison to TRAIL alone (Figure 3A). Chalcones cooperate with TRAIL to induce apoptosis in cancer cells (Figure 3B).

When HeLa cells were treated with the same concentrations of TRAIL and tested compounds, the percentage of apoptotic cells determined by annexin V-FITC staining using flow cytometry was elevated to $32.9 \% \pm 1.1 \%-44.1 \% \pm 1.3 \%$ for chalcone, to $51.5 \% \pm 1.2 \%-61.7 \% \pm 1.2 \%$ for isobavachalcone, to $61.4 \% \pm 1.1 \%-72.7 \% \pm 1.0 \%$ for licochalcone $\mathrm{A}$, and to $62.0 \% \pm 1.2 \%-77.1 \% \pm 1.2 \%$ for xanthohumol.

Chalcones overcome the TRAIL-resistance of HeLa cells and markedly increase anticancer effect of death ligand. The annexin V-FITC staining visualized by fluorescence microscopy, supports the hypothesis that the apoptotic activity of TRAIL was augmented by chalcones in cancer cells (Figure 3C). The necrotic cell death percentage of HeLa cells examined by lactate dehydrogenase assay, Apoptest-FITC and Apoptotic \& Necrotic \& Healthy Cells Quantification Kit was near zero. Isobavachalcone, licochalcone A and xanthohumol exhibited strong cytotoxic and apoptotic effects in combination with TRAIL against cancer cells. Sensitization of cancer cells to TRAIL-mediated death by chalcones suggests the potential role of these compounds in augmentation of anticancer immune defense in which endogenous TRAIL takes part. 
Figure 3. Cytotoxic and apoptotic effects of tumor necrosis factor-related apoptosis-inducing ligand (TRAIL) in combination with chalcones in HeLa cancer cells. The cells were incubated for $24 \mathrm{~h}$ with TRAIL at the concentration of $100 \mathrm{ng} / \mathrm{mL}$ and chalcones at the concentrations of $25 \mu \mathrm{M}$ and $50 \mu \mathrm{M}$. The values represent mean $\pm \mathrm{SD}$ of three independent experiments performed in quadruplicate (*** $p<0.001$ compared with TRAIL). (a) Co-treatment of TRAIL with chalcones induced cytotoxicity in HeLa cells. The percentage of cell death was measured by MTT cytotoxicity assay; (b) Co-treatment of TRAIL with chalcones induced apoptosis in HeLa cells. Detection of apoptotic cell death by annexin V-FITC and propidium iodide staining using flow cytometry; (c) Co-treatment of TRAIL with chalcones induced apoptosis in HeLa cells: (1) control cells; (2) cells incubated with $100 \mathrm{ng} / \mathrm{mL}$ TRAIL; (3) cells incubated with $25 \mu \mathrm{M}$ chalcone; (4) cells incubated with $50 \mu \mathrm{M}$ chalcone; (5) cells incubated with $100 \mathrm{ng} / \mathrm{mL}$ TRAIL and $25 \mu \mathrm{M}$ chalcone; (6) cells incubated with $100 \mathrm{ng} / \mathrm{mL}$ TRAIL and $50 \mu \mathrm{M}$ chalcone; (7) cells incubated with $25 \mu \mathrm{M}$ isobavachalcone; (8) cells incubated with $50 \mu \mathrm{M}$ isobavachalcone; (9) cells incubated with $100 \mathrm{ng} / \mathrm{mL}$ TRAIL and $25 \mu \mathrm{M}$ isobavachalcone; (10) cells incubated with $100 \mathrm{ng} / \mathrm{mL}$ TRAIL and $50 \mu \mathrm{M}$ isobavachalcone; (11) cells incubated with $25 \mu \mathrm{M}$ licochalcone A; (12) cells incubated with $50 \mu \mathrm{M}$ licochalcone A; (13) cells incubated with $100 \mathrm{ng} / \mathrm{mL}$ TRAIL and $25 \mu \mathrm{M}$ licochalcone A; (14) cells incubated with $100 \mathrm{ng} / \mathrm{mL}$ TRAIL and $50 \mu \mathrm{M}$ licochalcone $\mathrm{A}$; (15) cells incubated with $25 \mu \mathrm{M}$ xanthohumol; (16) cells incubated with $50 \mu \mathrm{M}$ xanthohumol; (17) cells incubated with $100 \mathrm{ng} / \mathrm{mL}$ TRAIL and $25 \mu \mathrm{M}$ xanthohumol; (18) cells incubated with $100 \mathrm{ng} / \mathrm{mL}$ TRAIL and $50 \mu \mathrm{M}$ xanthohumol. Detection of apoptotic cell death by fluorescence microscopy using annexin V-FITC, Ethidium Homodimer III and Hoechst 33342 staining. The healthy cells (stained with Hoechst 33342) emitted blue fluorescence and apoptotic cells (stained with Annexin V-FITC and Hoechst 33342) emitted green and blue fluorescence (indicated by arrows). Cells undergoing apoptosis showed nuclei shrinkage, chromatin condensation and nuclei fragmentation.

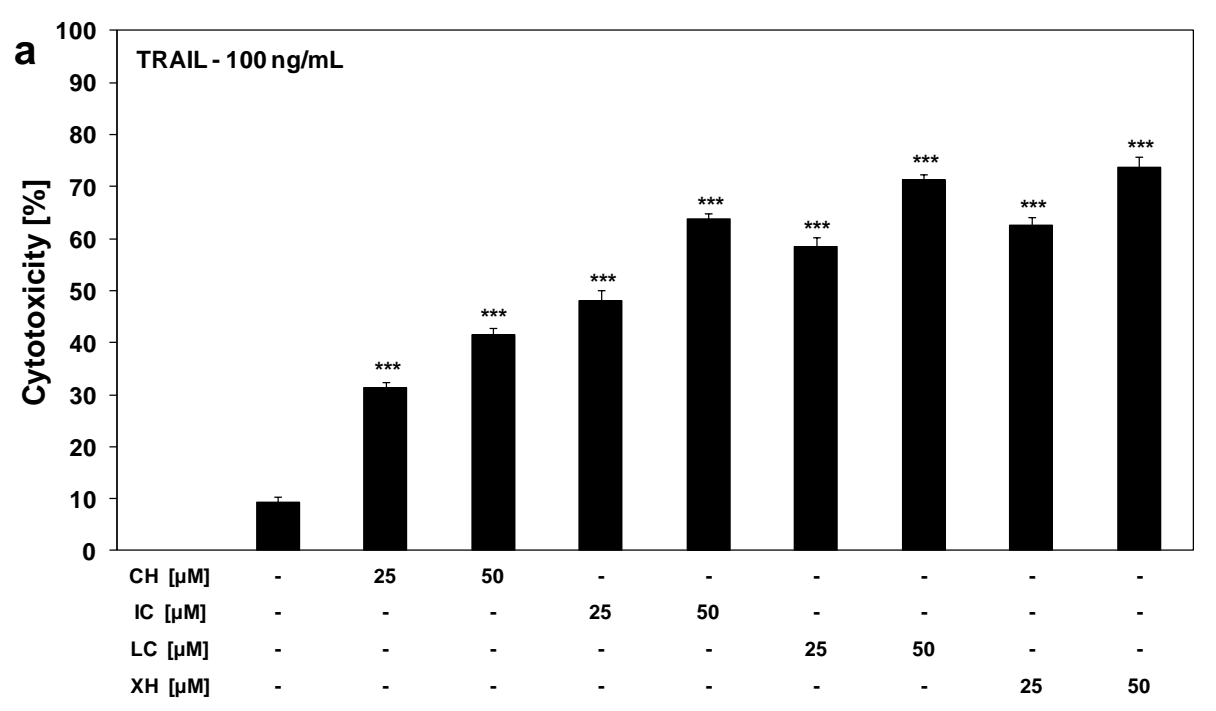


Figure 3. Cont.

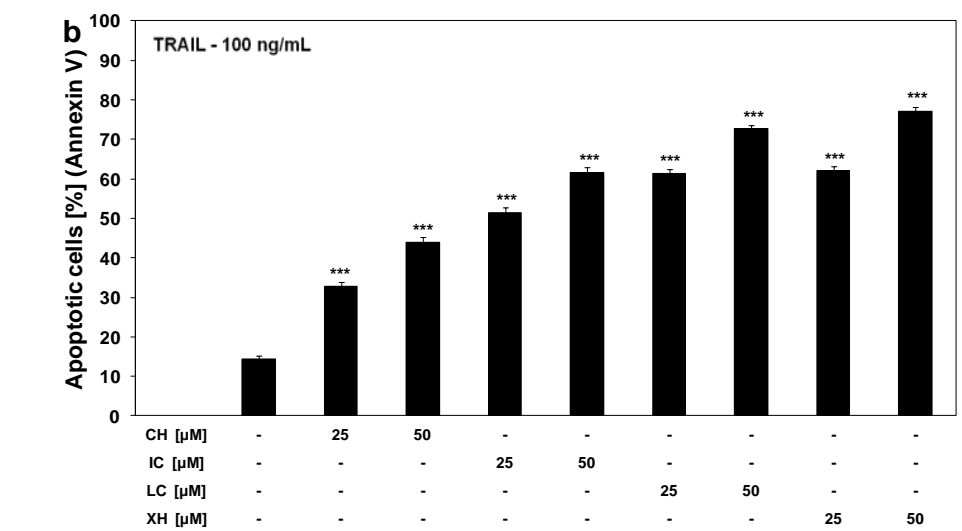

C
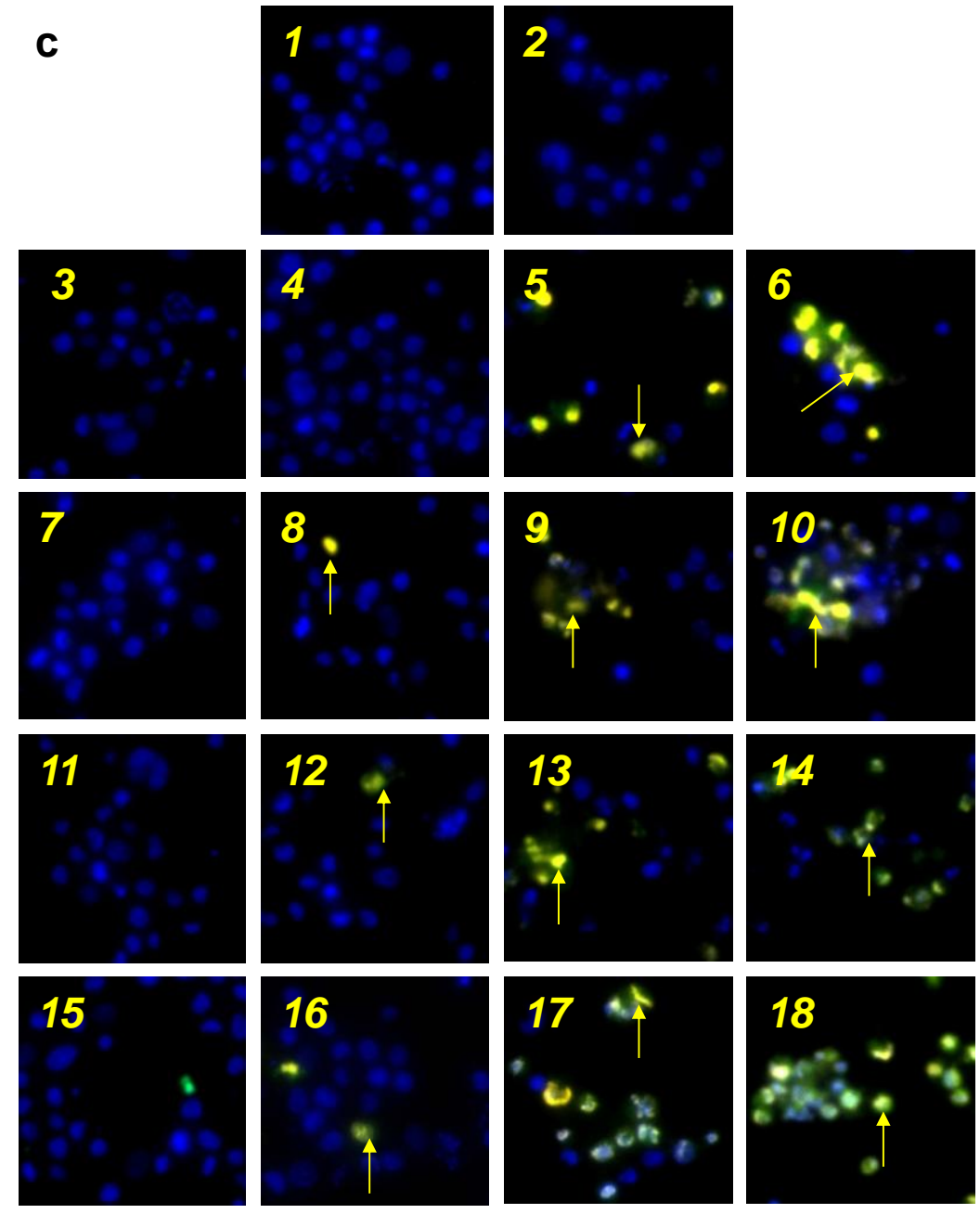

In our previous tests we showed that chalcone, licochalcone A, isobavachalcone, xanthohumol reversed TRAIL-resistance in LNCaP prostate cancer cells (however, we did not study the mechanism in depth). Three similar studies with flavokawain B, isoliquiritigenin and butein demonstrated that chalcones synergistically with TRAIL mediate apoptosis in malignant tumor cells principally by induction of death receptor TRAIL-R2 (DR5) [47-50]. Tang et al. show the sensitization of PC3 prostate cancer to TRAIL-induced apoptosis by flavokawain B via increase of TRAIL-R2 and pro-apoptotic protein Bim expression and decrease of anti-apoptotic proteins XIAP and survivin in DU145 and PC3 prostate cancer cell [50]. Yoshida et al. indicated that isoliquiritigenin overcomes 
TRAIL-resistance in HT29 human colon cancer cells through up-regulation of TRAIL-R2 expression [47]. Kim describes the augmentation of TRAIL-mediated apoptosis in U937 human leukemia incubated with butein by increase of TRAIL-R2 expression and the caspase-3 activation [48]. Moon et al. confirm the role of up-regulation of TRAIL-R2 expression caused by butein in enhancement of TRAIL-induced apoptosis in Hep3B hapatoma cells [49]. Strategies for overcoming resistance to TRAIL-mediated apoptosis include direct targeting of death receptor expression [6,12].

\subsection{Chalcones Enhance TRAIL-Induced Apoptosis in HeLa Cancer Cells through Up-Regulation of TRAIL-R2}

Molecular insights into the regulation of apoptosis and defects in apoptosis signaling will help define the TRAIL-resistance of cancer cells and will provide new approaches for preventive or therapeutic intervention against tumors. TRAIL is one of several members of the TNF superfamily that induce apoptosis through engagement of death receptors [12]. Expression levels of TRAIL-R1/DR4 and/or TRAIL-R2/DR5 on the cancer cell surface may play a critical role in intensity and/or duration of death receptor-mediated signaling in response to death ligands [5,6]. We analyzed the expression of TRAIL-R1 and TRAIL-R2 proteins in HeLa cells after 24-hour treatment with chalcones at the concentration of $25 \mu \mathrm{M}$ by flow cytometry (Figure 4 ).

Figure 4. Effects of chalcones on death receptor expression in HeLa cancer cells. The cells were incubated for $24 \mathrm{~h}$ with compounds at the concentration of $25 \mu \mathrm{M}$. The surface expression of (a) TRAIL-R1 and (b) TRAIL-R2 on cancer cell was determined by flow cytometry. The values represent mean $\pm \mathrm{SD}$ of three independent experiments performed in quadruplicate.
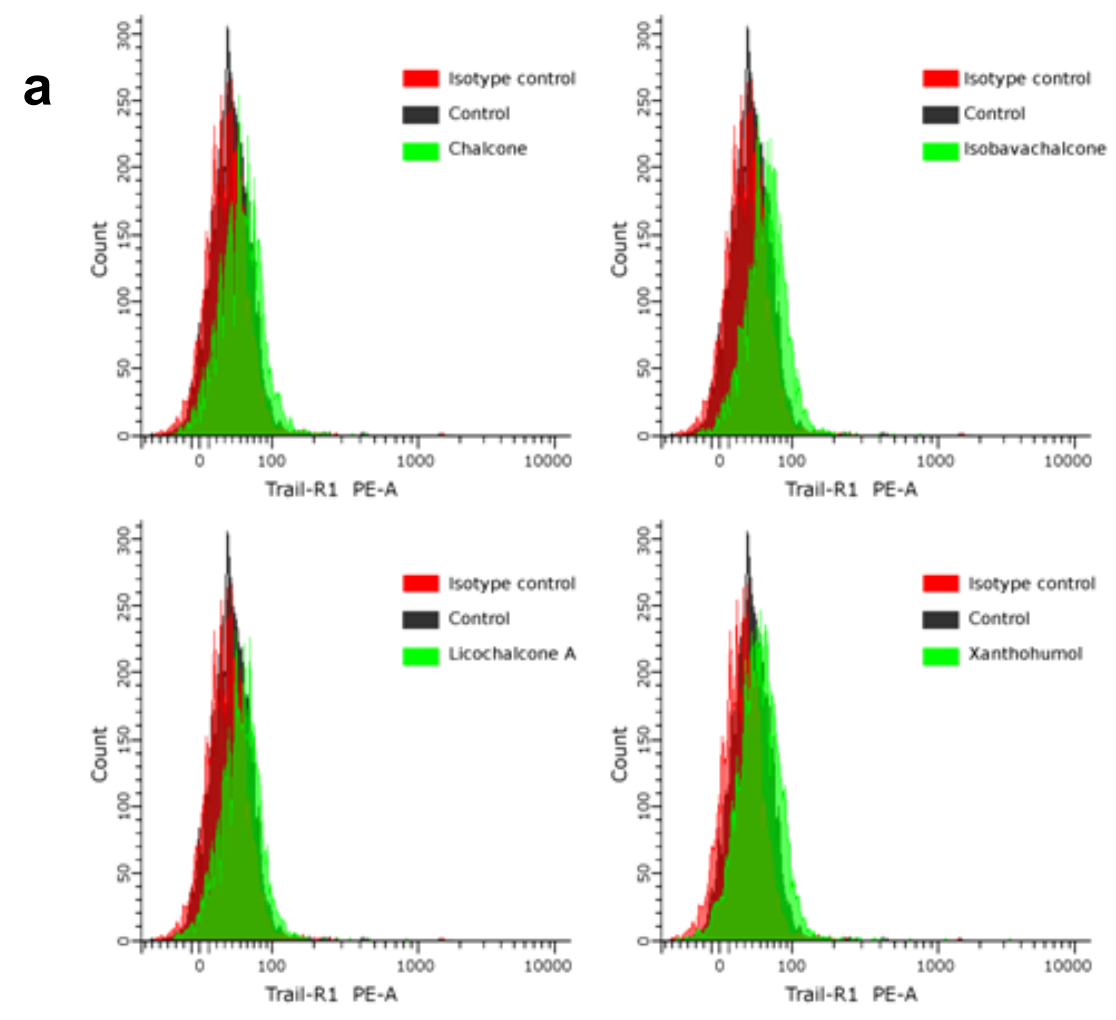
Figure 4. Cont.

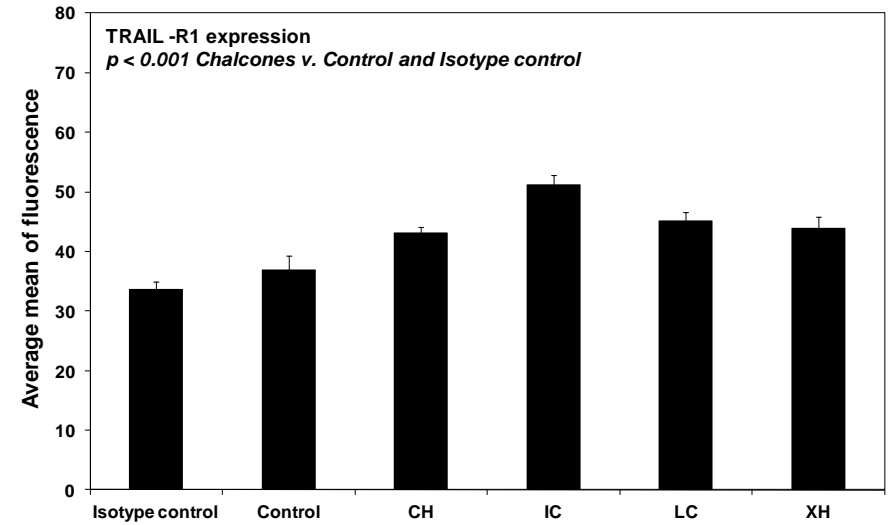

b
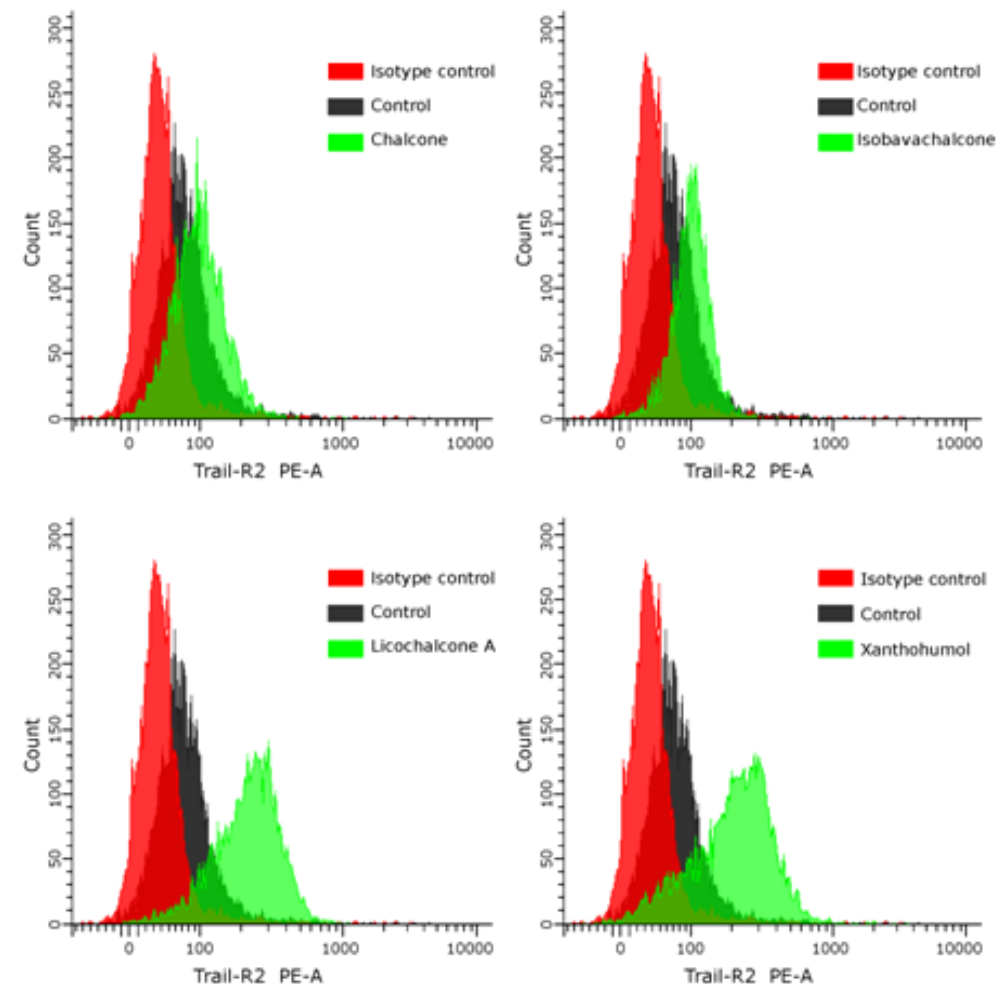

250

TRAIL -R2 expression

$p<0.001$ Chalcones v. Control and Isotype control

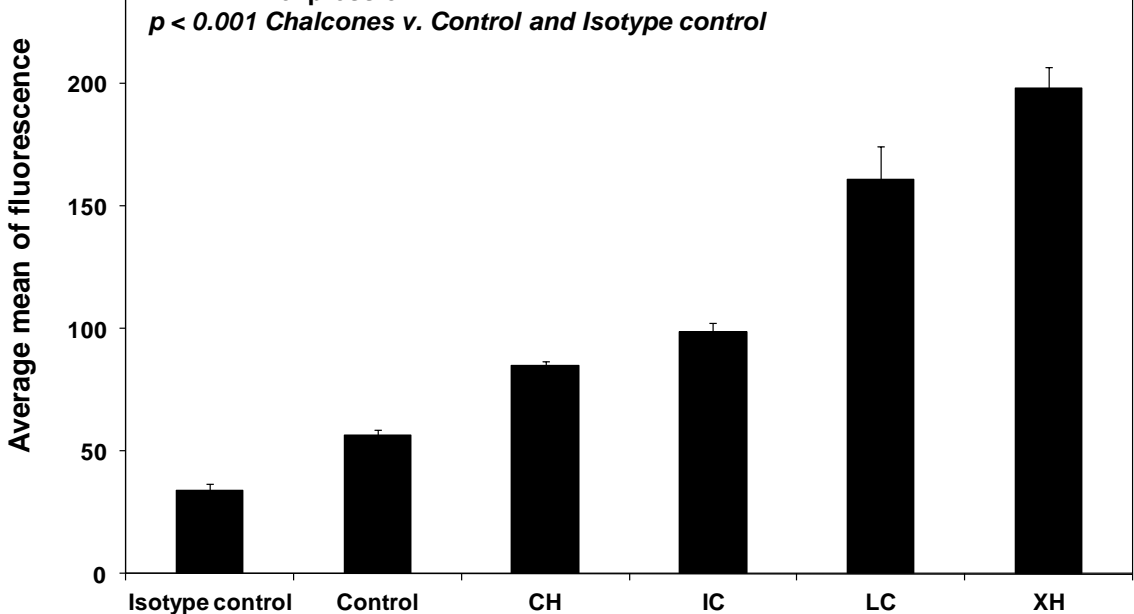


Chalcones significantly increase TRAIL-R2 protein levels on the cell surface. The compounds have a little, but also significant effect on TRAIL-R1 protein levels. To determine that the induction of apoptosis by the combination of TRAIL and chalcones was mediated through death receptor TRAIL-R2, we used the TRAIL-R2/Fc chimera protein, which has a dominant negative function against TRAIL-R2.

The TRAIL-R2/Fc efficiently blocked apoptosis caused by the co-treatment of TRAIL with chalcones (Figure 5). These data suggested that chalcones sensitize cancer cells to TRAIL through the extrinsic (receptor) apoptotic pathway via affecting TRAIL-R2.

Figure 5. TRAIL-R2/Fc chimera block apoptosis induced by the combination of TRAIL and chalcones in HeLa cancer cells. The cells were incubated for $24 \mathrm{~h}$ with $100 \mathrm{ng} / \mathrm{mL}$ TRAIL and/or $50 \mu \mathrm{M}$ chalcones with or without $1 \mu \mathrm{g} / \mathrm{mL}$ TRAIL-R2/Fc chimera proteins. Apoptotic cell death was detected by annexin V-FITC staining using flow cytometry. The values represent mean $\pm \mathrm{SD}$ of three independent experiments performed in duplicate.

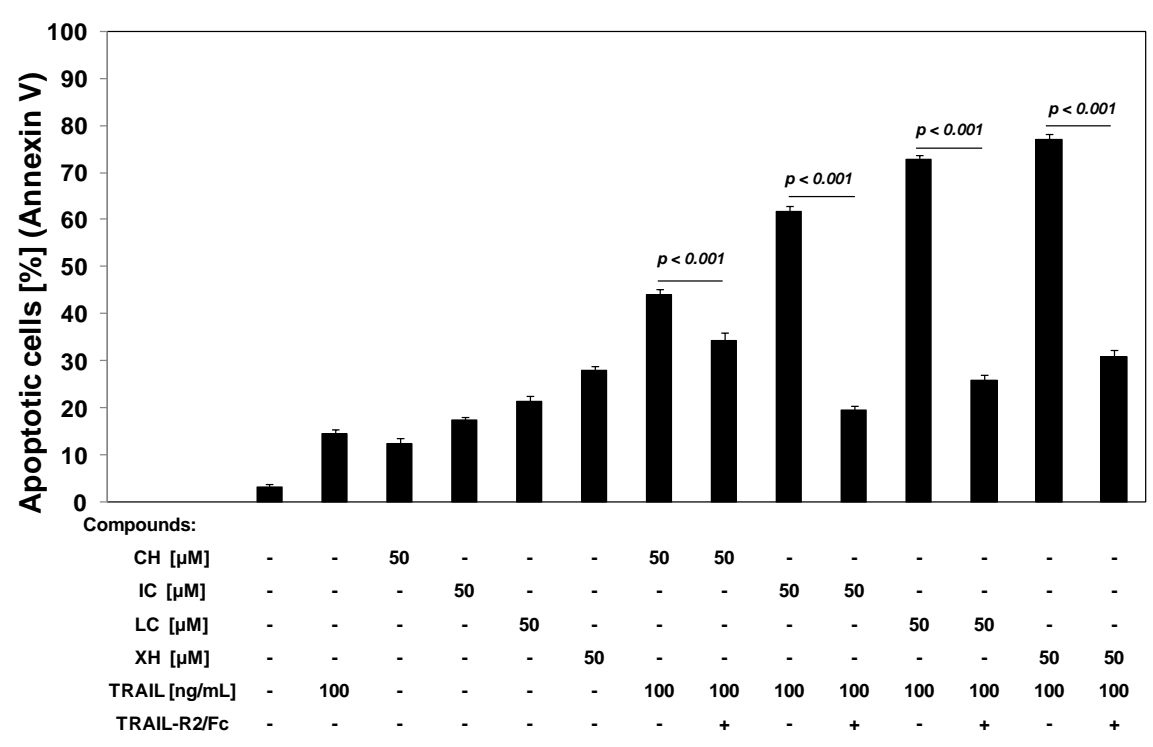

TRAIL-R2 up-regulation has become the most important strategy employed by polyphenols to sensitize TRAIL-resistant cancer cells to TRAIL-mediated apoptosis. Many recent studies have revealed that TRAIL-R2 may play a more prominent role than TRAIL-R1 in TRAIL-mediated apoptotic signaling, especially in cancer cells derived from solid tumors [6,12,51]. Numerous findings support the fact that TRAIL-resistance in cancer cells can be reversed by modulation of TRAIL-R 2 by polyphenols, including flavonoids [11,16,38,51-60]. Among chalcones tested in combination with TRAIL, flavokawain B, isoliquiritigenin and butein have induced TRAIL-R2 expression so far [47-50]. An increase of TRAIL-R2 expression and abrogation of TRAIL-resistance in cancer cells has been attributed to various flavonoids belonging to the flavonols, flavanones, isoflavones, flavones and flavonolignans subclass. Quercetin, kaempferol (flavonols) [52-55], naringenin, 6-hydroxy-flavanone, 6-propionoxyflavanone (flavanones) [51,56], biochanin A (isoflavones) [11], apigenin, luteolin, wogonin, baicalein (flavones) [38,56-59], and silibinin (flavonolignans) [60] enhance TRAIL-mediated death in cancer cells also by increase of TRAIL-R2 mRNA and/or TRAIL-R2 protein levels. 


\section{Experimental Section}

\subsection{Reagents}

Soluble recombinant human TRAIL (rhsTRAIL) was purchased from PeproTech Inc. (Rocky Hill, NJ, USA). Human recombinant TRAIL-R2/Fc chimera protein was obtained from R \& D Systems (Minneapolis, MN, USA). The four chalcones: chalcone (trans-benzylideneacetophenone) (CH), isobavachalcone (2',4',4-trihydroxy-3'-[3'-methylbut-3'-ethyl]chalcone) (IC), licochalcone-A (E-3-[5-(1,1-diethyl-2-propenyl) -4-hydroxy-2-methoxyphenyl]-1-(4-hydroxypenyl)-2-propen-1-one) (LC) and xanthohumol (2',4,4'-tri-hydroxy-3'-prenyl-6'-methoxychalcone) (XH) were obtained from Alexis Biochemicals (Lausanne, Switzerland). The compounds were dissolved in DMSO (50 $\mathrm{mM}$ ) to a final concentration of $0.1 \%(v / v)$ in the culture media.

\subsection{Cancer Cell Culture}

The experiments were performed on a HeLa human cervical cancer cell line obtained from DSMZ (Deutsche Sammlung von Mikroorganismen und Zellkulturen) GmbH-German Collection of Microorganism and Cell Cultures (Braunschweig, Germany). The HeLa cells were grown in monolayer cultures in RPMI 1640 containing $10 \%$ fetal bovine serum with $4 \mathrm{mM}$ L-glutamine, $100 \mathrm{U} / \mathrm{mL}$ penicillin and $100 \mu \mathrm{g} / \mathrm{mL}$ streptomycin. The cells were maintained at $37{ }^{\circ} \mathrm{C}$ in atmosphere with $5 \% \mathrm{CO}_{2}$ [13,39]. All reagents for cell culture were purchased from PAA Laboratories (Pasching, Austria).

\subsection{Detection of Cell Death Using MTT Cytotoxicity Assay}

The cytotoxicity was determined by the 3-(4,5-dimethylthiazol-2-yl)-2,5-diphenyltetrazolium bromide (MTT) assay as described previously [61,62]. The HeLa cells $\left(2.5 \times 10^{5} / \mathrm{mL}\right)$ were seeded $24 \mathrm{~h}$ before the experiments in a 96-well plate and incubated with TRAIL $(100 \mathrm{ng} / \mathrm{mL})$ and/or chalcones $(25 \mu \mathrm{M}$ and $50 \mu \mathrm{M})$ for $24 \mathrm{~h}$. Next, the medium was removed and $20 \mu \mathrm{L}$ MTT solutions prepared at $5 \mathrm{mg} / \mathrm{mL}$ (Sigma Chemical Company, St. Louis, MO, USA) were added to each well for $4 \mathrm{~h}$. The resulting crystals were dissolved in DMSO. Controls included native cells and medium alone. The spectrophotometric absorbance of each well was measured using a microplate reader (ELx 800, Bio-Tek Instruments Inc., Winooski, VT, USA) at $550 \mathrm{~nm}$. The cytotoxicity was calculated by the formula: percent cytotoxicity (cell death) $=[1-$ (absorbance of experimental wells/absorbance of control wells) $] \times 100 \%$.

\subsection{Lactate Dehydrogenase Release Assay}

Lactate dehydrogenase (LDH) is a stable cytosolic enzyme released upon membrane damage in necrotic cells. Measurement of LDH activity was performed using a commercial cytotoxicity assay kit (Roche Diagnostics GmbH, Mannheim, Germany). The HeLa cells were treated with TRAIL (100 ng/mL) and/or chalcones $(25 \mu \mathrm{M}$ and $50 \mu \mathrm{M})$ for the indicated period of time. The sample solution (supernatant) was removed and LDH released from cells was detected in culture supernatants with a coupled enzymatic assay, resulting in conversion of a tetrazolium salt into red formazan 
product. The maximal release was obtained after treating control cells with $1 \%$ Triton $\mathrm{X}-100$ for $10 \mathrm{~min}$ at room temperature [15,63]. The necrotic percentage was expressed using the formula: (sample value/maximal release) $\times 100 \%$.

\subsection{Detection of Apoptotic Cell Death by Flow Cytometry}

Apoptosis was determined by flow cytometry using the Apoptest-FITC Kit with annexin V (Dako, Glostrup, Denmark). HeLa cells $\left(2.5 \times 10^{5} / \mathrm{mL}\right)$ were seeded in 24-well plates for $24 \mathrm{~h}$ prior to experimentation and then exposed to TRAIL $(100 \mathrm{ng} / \mathrm{mL})$ and/or chalcones $(25 \mu \mathrm{M}$ and $50 \mu \mathrm{M})$ for $24 \mathrm{~h}$. After the incubation, the cells were washed twice with phosphate-buffered saline solution (PBS) and resuspended in $500 \mu \mathrm{L}$ of binding buffer. The cell suspension $(290 \mu \mathrm{L})$ was then incubated with $5 \mu \mathrm{L}$ of annexin V-FITC and $5 \mu \mathrm{L}$ of propidium iodide for $10 \mathrm{~min}$ at room temperature in the dark. The population of annexin V-positive cells was evaluated by flow cytometry (LSR II, Becton Dickinson Immunocytometry Systems, San Jose, CA, USA) [39,63].

\subsection{Detection of Apoptotic Cell Death by Fluorescence Microscopy}

Apoptotic cells were quantified by the fluorescence microscopy method using the Apoptotic \& Necrotic \& Healthy Cells Quantification Kit from Biotium, Inc. (Hayward, CA, USA) according to the manufacturer's instruction [13,25]. The HeLa cells $\left(2.5 \times 10^{5} / \mathrm{mL}\right)$ were seeded $24 \mathrm{~h}$ before the experiments in a 24 -well plate. TRAIL $(100 \mathrm{ng} / \mathrm{mL})$ and/or chalcones $(25 \mu \mathrm{M}$ and $50 \mu \mathrm{M})$ were added to cancer cells, and $24 \mathrm{~h}$ later the cells were washed with PBS and detached from cell culture wells by trypsin. Next, the cells were centrifuged to discard supernatant, washed with PBS and resuspended in binding buffer $(100 \mu \mathrm{L} /$ sample). To each tube there was added: $5 \mu \mathrm{L}$ Annexin V-FITC, $5 \mu \mathrm{L}$ Ethidium Homodimer III and $5 \mu \mathrm{L}$ Hoechst 33342 solutions. The samples were incubated at room temperature for $15 \mathrm{~min}$ in the dark. After staining, the cancer cells were washed with Binding Buffer, placed on a glass slide and covered with a glass coverslip. The stained cells were observed under a fluorescence inverted microscope IX51 (Olympus, Tokyo, Japan) using filter set for FITC, TRITC and DAPI. The healthy cells (stained with Hoechst 33342) emitted blue fluorescence, apoptotic cells (stained with Annexin V-FITC and Hoechst 33342) emitted green and blue fluorescence whereas necrotic cells (stained with Ethidium Homodimer III and Hoechst 33342) emitted red and blue fluorescence.

\subsection{Analysis of Death Receptor Expression on the Cancer Cell Surface by Flow Cytometry}

The cell surface expression of death receptors TRAIL-R1 and TRAIL-R2 was detected by flow cytometry (LSR II, Becton Dickinson Immunocytometry Systems). HeLa cells $\left(2.5 \times 10^{5} / \mathrm{mL}\right)$ were seeded in 24-well plates for $24 \mathrm{~h}$ and exposed to chalcones $(25 \mu \mathrm{M})$ for $24 \mathrm{~h}$. Cells were then harvested using solution of trypsin and ethylenediaminetetraacetic acid, washed twice in PBS and resuspended in PBS containing $0.5 \%$ bovine serum albumin. Cells were incubated with $10 \mu \mathrm{L}$ phycoerythrin-conjugated anti-TRAIL-R1 or anti-TRAIL-R2 monoclonal antibody (R \& D Systems) at $4{ }^{\circ} \mathrm{C}$ for $45 \mathrm{~min}$. After staining, the cells were washed with PBS and analyzed using flow 
cytometry [51,64]. The control sample (isotype control) consisted of cells in a separate tube treated with phycoerythrin-labelled mouse $\operatorname{IgG}_{1}$ or mouse $\operatorname{IgG}_{2 \mathrm{~B}}$ ( $\mathrm{R} \& \mathrm{D}$ Systems).

\subsection{Statistical Analysis}

The results are expressed as means \pm SD obtained from three separate experiments performed in quadruplicate $(n=12)$. Statistical significance was evaluated using Student's $t$-test. $p$-values $<0.05$ were considered significant.

\section{Conclusions}

Targeting a TRAIL-induced apoptotic signaling pathway in tumor cells by polyphenols is one of the crucial issues in cancer chemoprevention. Chalcone, isobavachalcone, licochalcone-A and xanthohumol markedly augment the anticancer activity of TRAIL in HeLa cells. The chalcones sensitize TRAIL-resistant cancer cells by engaging extrinsic apoptotic pathway with increased expression of TRAIL-R2 receptor. The study suggests that the overcoming of TRAIL-resistance by chalcones may be one of the mechanisms responsible for their cancer preventive effects.

\section{Acknowledgments}

This work was supported by a research grant KNW-1-017/P/1/0 from the Medical University of Silesia in Katowice (Poland).

\section{References}

1. Holoch, P.A.; Griffith, T.S. TNF-related apoptosis-inducing ligand (TRAIL): A new path to anti-cancer therapies. Eur. J.Pharmacol. 2009, 625, 63-72.

2. Lee, J.Y.; Huerta-Yepez, S.; Vega, M.; Baritaki, S.; Spandidos, D.A.; Bonavida, B. The NO TRAIL to YES TRAIL in cancer therapy. Int. J. Oncol. 2007, 31, 685-691.

3. Szliszka, E.; Zydowicz, G.; Janoszka, B.; Dobosz, C.; Kowalczyk-Ziomek, G.; Krol, W. Ethanolic extract of Brazilian green propolis sensitizes prostate cancer cells to TRAIL-induced apoptosis. Int. J. Oncol. 2011, 38, 941-953.

4. Mellier, G.; Huang, S.; Shenoy, K.; Pervaiz, S. TRAILing death in cancer. Mol. Aspects Med. 2010, 31, 93-112.

5. Szliszka, E.; Mazur, B.; Zydowicz, G.; Czuba, Z.P.; Krol, W. TRAIL-induced apoptosis and expression of death receptor TRAIL-R1 and TRAIL-R2 in bladder cancer cells. Folia Histochem. Cytobiol. 2009, 47, 579-585.

6. Mahalingam, D.; Szegezdi, E.; Keane, M.; de Jong, S.; Samali, A. TRAIL receptor signalling and modulation: Are we on the right TRAIL? Cancer Treat. Rev. 2009, 35, 280-288.

7. Qiu, B.; Sun, X.; Zhang, D.; Wang, Y.; Tao, J.; Ou, S. TRAIL and paclitaxel synergize to kill U87 cells and U87-derived stem-like cells in vitro. Int. J. Mol. Sci. 2012, 13, 9142-9156.

8. Stolfi, C.; Pallone, F.; Monteleone, G. Molecular targets of TRAIL-sensitizing agents in colorectal cancer. Int. J. Mol. Sci. 2012, 13, 7886-7901. 
9. Zhang, L.; Fang, B. Mechanisms of resistance to TRAIL-induced apoptosis in cancer. Cancer Gene Ther. 2005, 12, 228-237.

10. Szliszka, E.; Bronikowska, J.; Majcher, A.; Miszkiewicz, J.; Krol, W. Enhanced sensitivity of hormone-refractory prostate cancer cells to tumor necrosis factor-related apoptosis-inducing ligand (TRAIL) mediated cytotoxicity by taxanes. Cent. Eur. J. Urol. 2009, 62, 29-34.

11. Szliszka, E.; Czuba, Z.P.; Mertas, A.; Paradysz, A.; Krol, W. The dietary isoflavone biochanin-A sensitizes prostate cancer cells to TRAIL-induced apoptosis. Urol. Oncol. 2011, doi:10.1016/j.urolonc.2011.01.019.

12. Russo, M.; Mupo, A.; Spagnuolo, C.; Russo, G.L. Exploring death receptor pathways as selective targets in cancer therapy. Biochem. Pharmacol. 2010, 80, 674-682.

13. Szliszka, E.; Czuba, Z.P.; Jernas, K.; Krol, W. Dietary flavonoids sensitize HeLa cells to tumor necrosis factor-related apoptosis-inducing ligand (TRAIL). Int. J. Mol. Sci. 2008, 9, 56-64.

14. Szliszka, E.; Gebka, J.; Bronikowska, J.; Krol, W. Dietary flavones enhance the effect of tumor necrosis factor-related apoptosis-inducing ligand (TRAIL) on bladder cancer cells. Cent. Eur. J. Urol. 2010, 63, 138-143.

15. Bronikowska, J.; Szliszka, E.; Czuba, Z.P.; Zwolinski, D.; Szmydki, B.; Krol, W. The combination of TRAIL and isoflavones enhances apoptosis in cancer cells. Molecules 2010, 15, 2000-2015.

16. Szliszka, E.; Krol, W. The role of dietary polyphenols in tumor necrosis factor-related apoptosis inducing ligand (TRAIL)-induced apoptosis for cancer chemoprevention. Eur. J. Cancer Prev. 2011, 20, 63-69.

17. Go, M.L.; Wu, X.; Liu, X.L. Chalcones: An update on cytotoxic and chemopreventive properties. Curr. Med. Chem. 2005, 12, 481-499.

18. Orlikova, B.; Tasdemir, D.; Golais, F.; Dicato, M.; Dieterich, M. Dietary chalcones with chemopreventive and chemotherapeutic potential. Genes Nutr. 2011, 6, 125-147.

19. Rahman, R.N.; Zakaria, I.I.; Salleh, A.B.; Basri, M. Enzymatic properties and mutational studies of chalcone synthase from physcomitrella patens. Int. J. Mol. Sci. 2012, 13, 9673-9691.

20. Okuyama, T.; Takata, M.; Takayasu, J.; Hasegawa, T.; Tokuda, H.; Nishino, A.; Nishino, H.; Iwashima, A. Anti-tumor-promotion by principles obtained from Angelica keiskei. Planta Med. 1991, 57, 242-246.

21. Gerhauser, C.; Alt, A.; Heiss, E.; Gamal-Eldeen, A.; Klimo, K.; Knauft, J.; Neumann, I.; Scherf, H.R.; Frank, N.; Bartsch, H.; et al. Cancer chemopreventive activity of xanthohumol, a natural product derived from hop. Mol. Cancer Ther. 2002, 1, 959-969.

22. Haraguchi, H.; Inoue, J.; Tamura, Y.; Mizutani, K. Antioxidative components of Psoralea corylifolia (Leguminosae). Phytother. Res. 2002, 16, 539-544.

23. Fu, Y.; Hsieh, T.C.; Guo, J.; Kunicki, J.; Lee, M.Y.; Darzynkiewicz, Z.; Wu, J.M. Licochalcone-A, a novel flavonoid isolated from licorice root (Glycyrrhiza glabra), causes G2 and late-G1 arrests in androgen-independent PC-3 prostate cancer cells. Biochem. Biophys. Res. Commun. 2004, 322, 263-270.

24. Desmulle, L.; Bellahcene, A.; Dhooge, W.; Comhaire, F.; Roelens, F.; Huvaere, K.; Heyerick, A.; Castronovo, V.; Dekeukeleire D. Antiproliferative properties of prenylated flavonoids from hops (Humulus lupulus L.) in prostate cancer cell lines. Phytomedicine 2006, 13, 732-734. 
25. Szliszka, E.; Czuba, Z.P.; Sedek, L.; Paradysz, A.; Krol, W. Enhanced TRAIL-mediated apoptosis in prostate cancer cells by the bioactive compounds neobavaisoflavone and psoralidin isolated from Psoralea corylifolia. Pharmacol. Rep. 2011, 63, 139-148.

26. Boumendjel, A.; Boccard, J.; Carrupt, P.A.; Nicolle, E.; Blanc, M.; Geze, A.; Choisnard, L.; Wouessidjewe, D.; Matera, E.L.; Dumontet, C. Antimitotic and antiproliferative activities of chalcones: forward structure-activity relationship. J. Med. Chem. 2008, 51, 2307-2310.

27. Echeverria, C.; Santibanez, J.S.; Donoso-Tauda, O.; Escobar, C.A.; Ramirez-Tagle, R. Structural antitumoral activity relationships of synthetic chalcones. Int. J. Mol. Sci. 2009, 10, 221-231.

28. Vogel, S.; Barbic, M.; Jurgenliemk, G.; Heilmann, J. Synthesis, cytotoxicity, anti-oxidative and anti-inflammatory activity of chalcones and influence of A-ring modifications on the pharmacological effect. Eur. J. Med. Chem. 2010, 45, 2206-2213.

29. Syam, S.; Abdelwahab, S.I.; Al-Mamary, M.A.; Mohan, S. Synthesis of chalcones with anticancer activities. Molecules 2012, 17, 6179-6195.

30. Eddouks, M.; Chattopadhyay, D.; De Feo, V.; Cho, W.C. Medicinal plants in the prevention and treatment of chronic diseases. Evid. Based Complement. Alternat. Med. 2012, 2012, 458274.

31. Thomasset, S.C.; Berry, T.P.; Garcea, G.; Marczylo, T.; Steward, W.P.; Gescher, A.J. Dietary polyphenolic phytochemicals - Promising cancer chemopreventive agents in humans? A review of their clinical properties. Int. J. Cancer 2007, 120, 451-458.

32. Nowakowska, Z. A review of anti-infective and anti-inflammatory chalcones. Eur. J. Med. Chem. 2007, 42, 125-137.

33. Szliszka, E.; Czuba, Z.P.; Mazur, B.; Sedek, L.; Paradysz, A.; Krol, W. Chalcones enhance TRAIL-induced apoptosis in prostate cancer cells. Int. J. Mol. Sci. 2010, 11, 1-13.

34. Szliszka, E.; Czuba, Z.P.; Mazur, B.; Paradysz, A.; Krol, W. Chalcones and dihydrochalcones augment TRAIL-mediated apoptosis in prostate cancer cells. Molecules 2010, 15, 5336-5353.

35. Szliszka, E.; Helewski, K.J.; Mizgala, E.; Krol, W. The dietary flavonol fisetin enhances the apoptosis-inducing potential of TRAIL in prostate cancer cells. Int. J. Oncol. 2011, 39, 771-779.

36. Cho W.C. Targeting the signaling pathways in cancer therapy. Expert Opin. Ther. Targets. 2012, $16,1-3$.

37. Szliszka, E.; Bronikowska, J.; Czuba, Z.P.; Krol, W. Isoflavones augment the effect of tumor necrosis factor-related apoptosis-inducing ligand (TRAIL) on prostate cancer cells. Cent. Eur. J. Urol. 2010, 63, 182-186.

38. Horinanka, M.; Yoshida, T.; Shiraishi, T.; Nakata, S.; Wakada, M.; Nakanishi, R.; Nishino, H.; Sakai, T. The combination of TRAIL and luteolin enhances apoptosis in human cervival cancer HeLa cells. Biochem. Biophys. Res. Commun. 2005, 333, 833-838.

39. Bronikowska, J.; Szliszka, E.; Jaworska, D.; Czuba, Z.P.; Krol, W. The coumarin psoralidin enhances anticancer effect of tumor necrosis factor-related apoptosis-inducing ligand (TRAIL). Molecules 2012, 17, 6449-6464.

40. Shen, K.H.; Chang, J.K.; Hsu, Y.L.; Kuo, P.L. Chalcone arrests cell cycle progression and induces apoptosis through induction of mitochondrial pathway and inhibition of nuclear factor kappa-B signalling in human bladder cancer cells. Basic Clin. Pharmacol. Toxicol. 2007, 101, 254-261. 
41. Hsu, Y.L.; Kuo, P.L.; Tzeng, W.S.; Lin, C.C. Chalcone inhibits the proliferation of human breast cancer cell by blocking cell cycle progression and inducing apoptosis. Food Chem. Toxicol. 2006, $44,704-713$.

42. Jing, H.; Zhou, X.; Dong, X.; Cao, J.; Zhu, H.; Lou, J.; Hu, Y.; He, Q.; Yang, B. Abrogation of Akt signaling by isobavachalcone contributes to its anti-proliferative effects towards human cancer cells. Cancer Lett. 2010, 294, 167-177.

43. Nishimura, R.; Tabata, K.; Arakawa, M.; Ito, Y.; Kimura, Y.; Akihisa, T.; Nagai, H.; Sakuma, A.; Kohno, H.; Suzuki, T. Isobavachalcone, a chalcone constituent of Angelica keiskei, induces apoptosis in neuroblastoma. Biol. Pharm. Bull. 2007, 30, 1878-1883.

44. Drenzek, J.G.; Seiler, N.L.; Jaskula-Sztul, R.; Rausch, M.M.; Rose, S.L. Xanthohumol decreases Notch1 expression and cell growth by cell cycle arrest and induction of apoptosis in epithelial ovarian cancer cell lines. Gynecol. Oncol. 2011, 122, 396-401.

45. Deeb, D.; Gao, X.; Jiang, H.; Arbab, A.S.; Dulchavsky, S.A.; Gautam, S.C. Growth inhibitory and apoptosis-inducing effects of xanthohumol, a prenylated chalone present in hops, in human prostate cancer cells. Anticancer Res. 2010, 30, 3333-3339.

46. Szliszka, E.; Krol, W. Soy isoflavones augment the effect of TRAIL-mediated apoptotic death in prostate cancer cells. Oncol. Rep. 2011, 26, 533-541.

47. Yoshida, T.; Horinaka, M.; Takara, M.; Tsuchihashi, M.; Mukai, N.; Wakada, M.; Sakai, T. Combination of isoliquiritigenin and tumor necrosis factor-related apoptosis-inducing ligand induces apoptosis in colon cancer HT29 cells. Environ. Health Prev. Med. 2008, 13, 281-287.

48. Kim, N. Butein sensitizes human leukemia cells to apoptosis induced by tumor necrosis factor-related apoptosis inducing ligand (TRAIL). Arch. Pharm. Res. 2008, 31, 1179-1186.

49. Moon, D.O.; Kim, M.O.; Choi, Y.H.; Kim, G.Y. Butein sensitizes human hepatoma cells to TRAIL-induced apoptosis via extracellular signal-regulated kinase/Sp1-dependent DR5 upregulation and NF-kappaB inactivation. Mol. Cancer Ther. 2010, 9, 1583-1595.

50. Tang, Y.; Li, X.; Liu, Z.; Simoneau, A.R.; Xie, J.; Zi, X. Flavokawain B, a kava chalcone, induces apoptosis via up-regulation of death-receptor 5 and Bim expression in androgen receptor negative, hormonal refractory prostate cancer cell lines and reduces tumor growth. Int. J. Cancer 2010, 127, 1758-1768.

51. Szliszka, E.; Kostrzewa-Susłow, E.; Bronikowska, J.; Jaworska, D.; Janeczko, T.; Czuba, Z.P.; Krol, W. Synthetic flavanones augment the anticancer effect of tumor necrosis factor-related apoptosis-inducing ligand (TRAIL). Molecules 2012, 17, 11693-11711.

52. Chen, W.; Wang, X.; Zhuang, J.; Zhang, L.; Lin, Y. Induction of death receptor 5 and suppression of surviving contribute to sensitization of TRAIL-induced cytotoxicity by quercetin in non-small lung cancer cells. Carcinogenesis. 2007, 28, 2114-2121.

53. Kim, J.Y.; Kim, E.H.; Park, S.S.; Lim, J.H.; Kwon, T.K.; Choi, K.S. Quercetin sensitizes human hepatoma cells to TRAIL-induced apoptosis via Sp1-mediated DR5 upregulation and proteasome-mediated c-FLIPS downregulation. J. Cell. Biochem. 2008, 105, 1386-1398.

54. Yoshida, T.; Konishi, M.; Horinaka, M.; Yasuda, T.; Goda, A.E.; Taniguchi, H.; Yano, K.; Wakada, M.; Sakai, T. Kaempferol sensitizes colon cancer cells to TRAIL-induced apoptosis. Biochem. Biophys. Res. Commun. 2008, 375, 129-133. 
55. Jung, Y.H.; Heo, J.; Lee, Y.J.; Kwon, T.K.; Kim, Y.H. Quercetin enhances TRAIL-induced apoptosis in prostate cancer cells via increased protein stability of death receptor 5. Life Sci. 2010, $86,351-357$.

56. Jin, C.Y.; Park, C.; Hwang, H.J.; Kim, G.Y.; Choi, B.T.; Kim, W.J.; Choi, Y.H. Naringenin up-regulates the expression of death receptor 5 and enhances TRAIL-induced apoptosis in human lung cancer A549 cells. Mol. Nutr. Food Res. 2011, 55, 300-309.

57. Horinaka, M.; Yoshida, T.; Shiraishi, T.; Nakata, S.; Wakada, M.; Sakai, T. The dietary flavonoid apigenin sensitizes malignant tumor cells to tumor necrosis factor-related apoptosis-inducing ligand. Mol. Cancer Ther. 2006, 5, 945-951.

58. Tanaguchi, H.; Yoshida, T.; Horinaka, M.; Yasuda, T.; Goda, A.E.; Konishi, M.; Wakada, M.; Kataoka, K.; Yoshikawa, T.; Sakai, T. Baicalein overcomes tumor necrosis factor-related apoptosis-inducing ligand resistance via two different cell specific pathways in cancer cells but not in normal cells. Cancer Res. 2008, 68, 8918-8927.

59. Ding, J.; Polier, G.; Köhler, R.; Giaisi, M.; Krammer, P.H.; Li-Weber, M. Wogonin and related natural flavones overcome tumor necrosis factor-related apoptosis inducing ligand (TRAIL) protein resistance of tumors by down-regulation of c-FLIP protein and up-regulation of TRAIL receptor 2 expression. J. Biol. Chem. 2012, 287, 641-649.

60. Son, Y.G.; Kim, E.H.; Kim, J.Y.; Kim, S.U.; Kwon, T.K.; Yoon, A.R.; Yun, C.O.; Choi, K.S. Silibinin sensitizes human glioma cells to TRAIL-mediated apoptosis via DR5 upregulation and downregulation of cFLIP and surviving. Cancer Res. 2007, 67, 8274-8284.

61. Tsai, C.F.; Yeh, W.L.; Huang, S.M.; Tan, T.W.; Lu, D.Y. Wogonin induces reactive oxygen species production and cell apoptosis in human glioma cancer cells. Int. J. Mol. Sci. 2012, 13, 9877-9892.

62. Szliszka, E.; Majcher, A.; Domino, M.; Pietsz, G.; Krol, W. Cytotoxic activity of tumor necrosis factor-related apoptosis-inducing ligand (TRAIL) against bladder cancer cells after using chemotherapeutic drugs. Urol. Pol. 2007, 60, 138-142.

63. Szliszka, E.; Czuba, Z.P.; Kawczyk-Krupka, A.; Sieron-Stoltny, A.; Sieron, A.; Krol, W. Chlorin-based photodynamic therapy enhances the effect of tumor necrosis factor-related apoptosis-inducing ligand (TRAIL) in bladder cancer cells. Med. Sci. Monit. 2012, 18, BR47-BR53.

64. Szliszka, E.; Zydowicz, G.; Mizgala, E.; Krol, W. Artepillin C (3,5-diprenyl-4-hydroxycinnamic acid) sensitizes prostate cancer LNCaP cells to TRAIL-induced apoptosis. Int. J. Oncol. 2012, 41, 818-828.

(C) 2012 by the authors; licensee MDPI, Basel, Switzerland. This article is an open access article distributed under the terms and conditions of the Creative Commons Attribution license (http://creativecommons.org/licenses/by/3.0/). 